\title{
Influence of Vanadium Microalloying on Deformation-Induced Pearlite Transformation of Eutectoid Steel
}

\author{
Zhen Cai ${ }^{1,2} \mathbb{D}$, Xinping Mao ${ }^{1,2}$, Siqian Bao ${ }^{1,3, *}$, Gang Zhao ${ }^{1,3}$ and Yaowen Xu ${ }^{1,3}$ \\ 1 The State Key Laboratory of Refractories and Metallurgy, Wuhan University of Science and Technology, \\ Wuhan 430081, China; caizhen198804@126.com (Z.C.); maoxinping@126.com (X.M.); \\ zhaogang@wust.edu.cn (G.Z.); xuyw10@126.com (Y.X.) \\ 2 Wuhan Branch of Baosteel Central Research Institute, Wuhan 430080, China \\ 3 Key Laboratory for Ferrous Metallurgy and Resources Utilization of Ministry of Education, \\ Wuhan University of Science and Technology, Wuhan 430081, China \\ * Correspondence: baosiqian@163.com; Tel.: +86-027-8648-7752
}

Received: 12 February 2019; Accepted: 20 February 2019; Published: 25 February 2019

\begin{abstract}
In order to investigate the influence of vanadium microalloying on deformation-induced pearlite transformation (DIPT) of eutectoid steel, thermomechanical simulation tests were carried out in this study. The following four compositions of vanadium microalloying were applied in the tests: vanadium free in Steel A, vanadium content of $0.1 \mathrm{mass} \%$ in Steel B, vanadium content of 0.27 mass $\%$ in Steel C, and vanadium content of 0.1 mass $\%$ with the addition of 0.02 mass $\% \mathrm{~N}$ in Steel D. The dissolution of vanadium and precipitation of vanadium carbides, nitrides, or carbonitrides and the effect of vanadium microalloying on the fraction and morphology of deformation-induced pearlite for different magnitudes of strain were examined, and the mechanism of the effect was elucidated. The results revealed that DIPT could be significantly improved by vanadium microalloying with the addition of $\mathrm{N}$ but decreased and postponed without the addition of $\mathrm{N}$ because vanadium nitrides or carbonitrides were precipitated in austenite under a small strain and facilitated the nucleation of pearlite both along the boundary of austenite grain (AG pearlite) and intragranular (IG pearlite). Moreover, transformation kinetics of DIPT was fitted and compared. The results further revealed that the rate of DIPT in vanadium-microalloyed steel with the addition of $\mathrm{N}$ was twice as fast as that in the vanadium-free steel. In order to ensure the complete spheroidization of lamellar cementites in vanadium-microalloyed steel, a comparison of the morphology of cementites revealed that a greater magnitude of strain was required.
\end{abstract}

Keywords: eutectoid steel; vanadium microalloying; deformation-induced pearlite transformation (DIPT); spheroidization

\section{Introduction}

High carbon steels with a fully pearlitic microstructure are widely applied in rail steels, spring steels, wire ropes, tire reinforcement, and high-strength bars because of their high strength, excellent wear resistance, and fatigue failure resistance [1-4]. However, the applications of high carbon steels are limited in precision instruments, tools, and small parts because of their susceptibility to brittle behavior. In order to overcome this limitation, the lamellar pearlitic microstructure in hot rolled products should be converted to spheroidized cementite particles because high carbon steels present better machinability and ductility under spheroidized conditions. Thus, the spheroidization of cementite has been widely studied in the past. Generally, such spheroidization was developed by annealing and it could be accelerated by the process of cold working before annealing, thermomechanical 
processing, and using certain heat treatment procedures [5-8]. More than a decade ago, researchers reported that the spheroidization time could be significantly reduced by the process of heavy deformation slightly below $\mathrm{A}_{1}$ temperature and therefore dynamic spheroidizing (DSX) was realized. It is possible to produce a microstructure consisting of ferrite in the submicrometer range and nanoscale spheroidized cementite provided the thermomechanical parameters (temperature, strain rate, and applied strain) are optimized. The advantages of producing a ultrafine, spheroidized microstructure via the technology include a significant increase in strength, ductility, and fracture toughness without expensive alloying additions or complicated heat treatments [9-12]. Generally, it was considered that the pearlite was dynamically induced during deformation and the induced pearlite spheroidized [13-16] under sustained deformation, the whole process was referred to as deformation-induced pearlite transformation (DIPT). In recent years the influence of deformation parameters on DIPT was extensively investigated [17,18].

Vanadium microalloying is considered as one of the most common methods in precipitation hardening [19-21] because of the high solubility of vanadium at relatively low temperatures during austenitization processes and the high affinity of carbon and especially nitrogen [22,23]. In addition to precipitation hardening, vanadium may facilitate the refining of the interlamellar spacing and the size of pearlite colonies $[24,25]$ and, thus, can further improve the comprehensive performance. However, the influence of vanadium microalloying on DIPT of high carbon steel has rarely been reported. As for deformation-induced ferrite transformation (DIFT) in low carbon steels, the relative results showed that the combination of DIFT and vanadium microalloying could further refine ferrite grains and DIFT was promoted by vanadium microalloying with the addition of nitrogen [26,27]. The objective of this study is to examine the dissolution of vanadium and precipitation of vanadium carbides, nitrides or carbonitrides in eutectoid steel and to determine the effect of vanadium microalloying on DIPT such as the fraction and the morphology of deformation-induced pearlite for different magnitudes of strains, and to elucidate the mechanism of the effect.

\section{Experimental Section}

The compositions of the four steels that are applied in this study are listed in Table 1. The steels were melted in an intermediate-frequency vacuum induction furnace. After the heating at $1100{ }^{\circ} \mathrm{C}$ for $2 \mathrm{~h}$, ingots were rolled into plates with a thickness of $20 \mathrm{~mm}$. The plate-shaped specimens were machined to cylinders with a diameter of $8 \mathrm{~mm}$ and a height of $12 \mathrm{~mm}$ for the thermomechanical simulation test, and THERMECMASTOR-Z dilatometry was used in the experiment.

The thermocouple was spot welded at the center of the sample around circumference surface. Induction heating and $\mathrm{N}_{2}$ were used for heating and cooling the samples to the desired temperature. A thermocouple feedback system was used for monitoring the temperature of the samples. Before conducting the test, the chamber was evacuated with a vacuum of approximately $0.05 \mathrm{~Pa}$ in order to minimize surface oxidation and decarburization. First, THERMECMASTOR-Z dilatometry was used for measuring the starting transformation temperature $A r_{1}$ at a cooling rate of $20^{\circ} \mathrm{C} / \mathrm{s}$. Then, the specimens were heated up to $1150{ }^{\circ} \mathrm{C}$ and held for $5 \mathrm{~min}$, cooled to $680^{\circ} \mathrm{C}$ at a cooling rate of $20^{\circ} \mathrm{C} / \mathrm{s}$ and pressed with a strain rate of $0.01 \mathrm{~s}^{-1}$ in order to obtain the true strain values of $0.05-1.39$, and finally cooled down to room temperature at a cooling rate of $50{ }^{\circ} \mathrm{C} / \mathrm{s}$ in order to retain transformed microstructure, as shown in Figure 1.

Optical microscopy (OLYMPUS, Tokyo, Japan) and scanning electron microscopy (SEM, FEI, Hillsboro, OR, USA) were used to observe the microstructures at the center of the deformed specimens. Image analysis was used to measure the quantity of pearlite and the grain size of deformation-induced microstructure. In addition, the electron back scattering diffraction (EBSD) was used to study the condition of the ferrite. The samples were electrolytically polished in a solution of perchloric acid and ethyl alcohol in the process of EBSD. The EBSD maps were scanned by using the Flamenco software with a step size of $0.3 \mu \mathrm{m}$ and analyzed by using the HKL-Channel 5 software (Oxford, London, UK). Transmission electron microscopy (TEM, JOEL, Tokyo, Japan) was used to observe the evolution 
of microstructure at different strains and analyze the precipitated vanadium carbides, nitrides or carbonitrides. Slices for TEM were cut from the thermal simulation samples, and were subsequently ground to less than $70 \mu \mathrm{m}$ and punched into $3 \mathrm{~mm}$ discs. Thin foils for TEM observation were prepared by twin-jet polishing with an electrolyte solution consisting of $6 \%$ perchloric acid and $94 \%$ ethyl alcohol below $-30^{\circ} \mathrm{C}$. Moreover, the carbon film extraction replica of TEM samples were also prepared. The TEM observation was carried out by using a JEM-2100 field emission high-resolution transmission electron microscopy (HRTEM) with an operating voltage of $200 \mathrm{kV}$. The components of the precipitated phase were characterized by EDS.

Table 1. Chemical compositions of the four steels used in the study.

\begin{tabular}{cccccccc}
\hline Steel & C & Si & Mn & P & S & V & N \\
\hline A & 0.798 & 0.21 & 0.33 & $<0.015$ & $<0.01$ & - & - \\
B & 0.80 & 0.21 & 0.32 & $<0.015$ & $<0.01$ & 0.094 & - \\
C & 0.78 & 0.22 & 0.33 & $<0.015$ & $<0.01$ & 0.27 & - \\
D & 0.79 & 0.22 & 0.35 & $<0.015$ & $<0.01$ & 0.098 & 0.02 \\
\hline
\end{tabular}

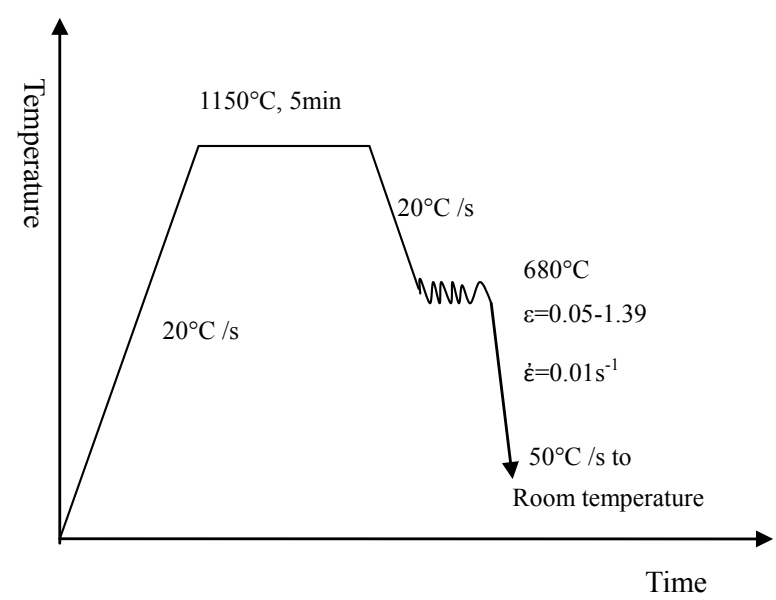

Figure 1. Thermomechanical simulation tests of steels.

\section{Results and Discussion}

\subsection{Theoretical Calculation of Vanadium Solubility and $A r_{1}$ Temperatures}

The equilibrium dissolved amounts of $V([\mathrm{~V}])$ and $C([\mathrm{C}])$ in austenite for V-bearing steels can be calculated by the following equation [28]:

$$
\log ([\mathrm{V}] \times[\mathrm{C}])_{\gamma}=6.72-9500 / \mathrm{T}
$$

where $[\mathrm{V}]$ is the amount (in mass \%) of vanadium dissolved in austenite in equilibrium at the given temperature and $[\mathrm{C}]$ is the $\mathrm{C}$ content (in mass $\%$ ) in the steel; $[\mathrm{V}] \times[\mathrm{C}]$ is the vanadium and carbon solubility (in mass \%) in austenite; and $T$ is the temperature.

At an austenization temperature of $1150^{\circ} \mathrm{C}(1423 \mathrm{~K})$, the equilibrium-dissolved vanadium quantity can be calculated by Equation (1), which is found to be $1.38 \%$ (C content of 0.8 mass $\%$ ). The contained vanadium was completely dissolved into austenite in Steels B and C.

In Steel $\mathrm{D}$ with the addition of $\mathrm{N}$, the equilibrium-dissolved amounts of $V([\mathrm{~V}])$ and $N([\mathrm{~N}])$ in austenite can be calculated by the following equation [28]:

$$
\log ([\mathrm{V}] \times[\mathrm{N}])_{\gamma}=3.63-8700 / \mathrm{T}
$$

where $[\mathrm{V}]$ is the amount (in mass \%) of vanadium dissolved in austenite in equilibrium at the given temperature and $[\mathrm{N}]$ is the $\mathrm{N}$ content (in mass\%) in steel; $[\mathrm{V}] \times[\mathrm{N}]$ is the vanadium and nitrogen 
solubility (in mass \%) in austenite; and $T$ is the temperature. At an austenization temperature of $1150{ }^{\circ} \mathrm{C}$ (1423 K), the equilibrium-dissolved vanadium quantity can be calculated by Equation (2), which is found to be $0.16 \%$ ( $\mathrm{N}$ content of $0.02 \mathrm{mass} \%$ ). The contained vanadium was completely dissolved into austenite in Steel D.

At a cooling rate of $20^{\circ} \mathrm{C} / \mathrm{s}$, the starting transformation temperatures, $A r_{1}$, of Steel A, Steel B, and Steel D were found to be 610,600 , and $598^{\circ} \mathrm{C}$, respectively. The thermal expansion due to the transformation from austenite to ferrite + cementite of Steel $\mathrm{C}$ was not detected because the cooling rate exceeded critical cooling rate of forming martensite and the transformation from austenite to ferrite + cementite did not occur. In Steels B, C, and D, the dissolved vanadium had not enough time to precipitate during cooling between $1150{ }^{\circ} \mathrm{C}$ and $680^{\circ} \mathrm{C}$ at a cooling rate of $20^{\circ} \mathrm{C} / \mathrm{s}$. Thus, the pearlite transformation was postponed and restrained at the dissolved vanadium content of 0.1 and especially 0.27 (in mass \%), respectively. As the solid solution of vanadium increases the diffusion activation energy of $C$ atoms and improves the stability of austenite [27]. It was observed that $\mathrm{N}$ showed little effect on the $A r_{1}$ temperature.

\subsection{Precipitation of Vanadium Carbides, Nitrides, or Carbonitrides}

In Steels $\mathrm{B}, \mathrm{C}$, and $\mathrm{D}$, the contained vanadium was dissolved into austenite at an austenization temperature of $1150{ }^{\circ} \mathrm{C}$ and did not precipitate at cooling to $680^{\circ} \mathrm{C}$ at a high cooling rate of $20^{\circ} \mathrm{C} / \mathrm{s}$. The equilibrium-dissolved amounts of vanadium in austenite without the addition of $\mathrm{N}$ at $680^{\circ} \mathrm{C}$ can be calculated from Equation (1), which is found to be $0.0007 \%$. In Steels B and C, the contained vanadium thermodynamically ought to precipitate. However, the precipitation of vanadium carbides is a diffusion-controlled process, which has an induction period [29]. Precipitates were not observed at strains of 0.22 and 0.51 . With the increase of strain to above 0.51 , most of the austenite transformed to ferrite + cementite (the transformation will be discussed later), the solubility of vanadium and carbon in ferrite is significantly lower as compared to in austenite [28], thus, vanadium carbides were formed in ferrite at strains of 0.91 and 1.39 in Steels B and C, the TEM observation of Steel C is shown in Figure 2.

With the addition of $\mathrm{N}$, the equilibrium-dissolved vanadium in austenite at $680{ }^{\circ} \mathrm{C}$ was decreased to $0.0001 \%$ as calculated by Equation (2) ( $\mathrm{N}$ content of 0.02 mass $\%$ ), thus the driving force for precipitation of vanadium nitrides is higher than that of vanadium carbides. Precipitates were observed under a small deformation with a strain of 0.05 in Steel D. Figure 3 shows fine particles in ferrite revealed by means of EDS in a carbon replica of the sample, the EDS gives a hint that the precipitates are either vanadium carbonitrides or vanadium nitrides or their mixture. It cannot be clearly identified, in which form they are because the sample is a carbon replica. There is a scientific evidence to suggest that vanadium nitrides or carbonitrides were precipitated first in austenite because the precipitates do not show morphology of interphase precipitation and Steel D exhibits different transformation behavior as compared to other V-bearing Steels. Vanadium might be precipitated first as almost pure nitrides, when the nitrogen is about to exhausted there is a gradual transition to form mixed carbonitrides around outside [30]. The precipitation of vanadium can be significantly improved by the addition of $\mathrm{N}$ because vanadium exhibits a higher affinity for nitrogen as compared to carbon. As the solubility of vanadium nitrides in austenite is lower than that of vanadium carbides, the driving force for precipitation of vanadium nitrides in austenite is significantly higher as compared to precipitation of vanadium carbides. Furthermore, precipitation of vanadium nitrides has an effect of inducing precipitation of vanadium carbonitrides or carbides by acting as nucleus and thus incubation time of precipitation shortens [31]. 

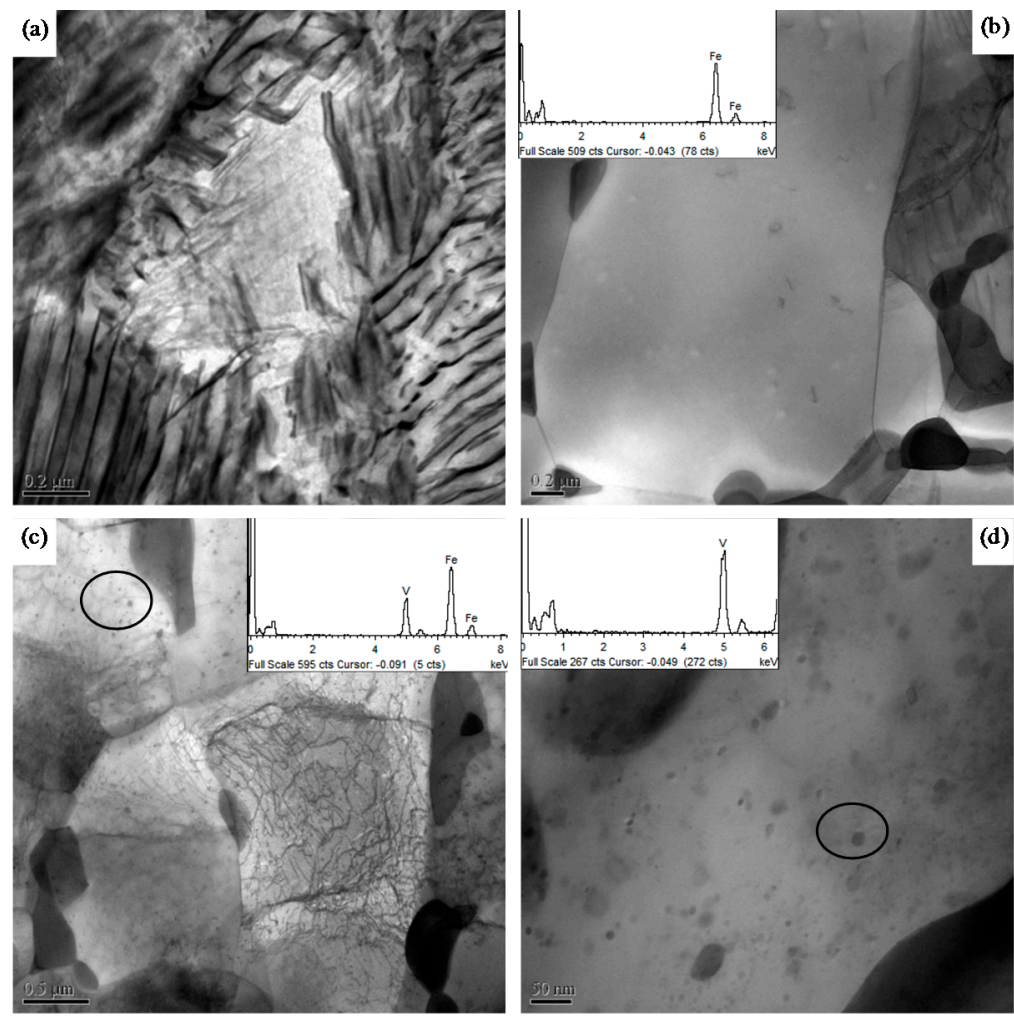

Figure 2. TEM observation of the thin foils of Steel $\mathrm{C}$ obtained by quenching following deformation at various strains: (a) 0.22, (b) 0.51, (c) 0.91, and (d) 1.39 .

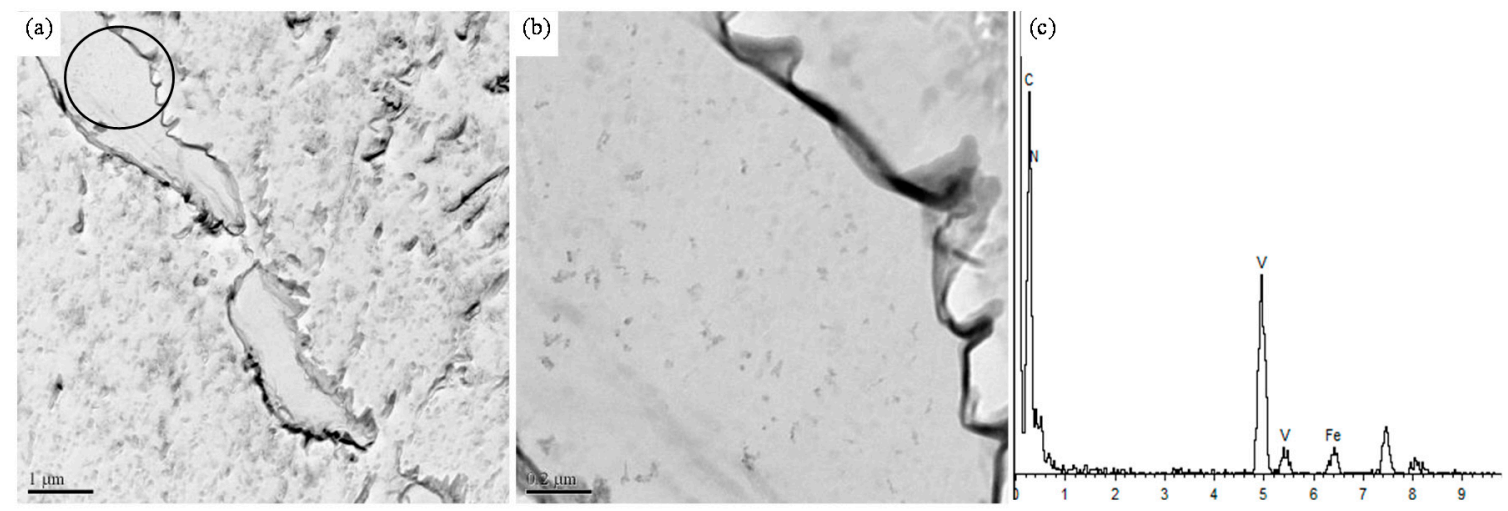

Figure 3. TEM observation of the carbon replica of Steel D obtained by quenching following deformation at a strain of 0.05. (a) precipitates distributed in the ferrite, (b) morphology of the precipitates, (c) chemical analysis of the precipitates by means of EDS

\subsection{Fraction of Deformation-Induced Pearlite}

The results of quantitative metallography measurement for deformation-induced pearlite in Steels A, B, C, and D for various amounts of strains with a strain rate of $0.01 \mathrm{~s}^{-1}$ and a deformation temperature of $680^{\circ} \mathrm{C}$ are shown in Figure 4. The fractions of deformation-induced pearlite increase with an increase in the strain in all the steels. The fraction in vanadium-microalloyed Steel B is lower as compared to that of vanadium-free Steel A at the same strain level when the strain is below 0.91, and the fraction further decrease with the content of vanadium in Steel $C$ increase as compared to Steel B. Furthermore, the fraction of deformation-induced pearlite in Steel D with $\mathrm{N}$ is the highest among the four steels. For instance, when the strain is 0.22 , the fractions of deformation-induced pearlite in Steels A, B, C, and D are $52 \%, 30.6 \%, 15.5 \%$, and $89.05 \%$, respectively. The morphology of the induced pearlite is shown in Figure 5. The dark phase is pearlite and the bright phase is martensite, 
which was transformed from austenite at the cooling process after deformation. In Steel A, pearlite nucleated along the boundary of austenite and grew toward inside, the boundary was nearly filled by pearlite, and some grains completely transformed to pearlite. On the other hand, pearlite occupied some part of the boundary of austenite in Steel B but nearly whole boundary in Steel C. However, the fraction of deformation-induced pearlite in Steel C was only one-half of that in Steel B because pearlite in Steel C grew more slowly and, thus, the fraction of pearlite was lower in spite of a higher rate of nucleation. Furthermore, most austenite transformed to pearlite and only a small amount of intragranular martensite remained in Steel D.

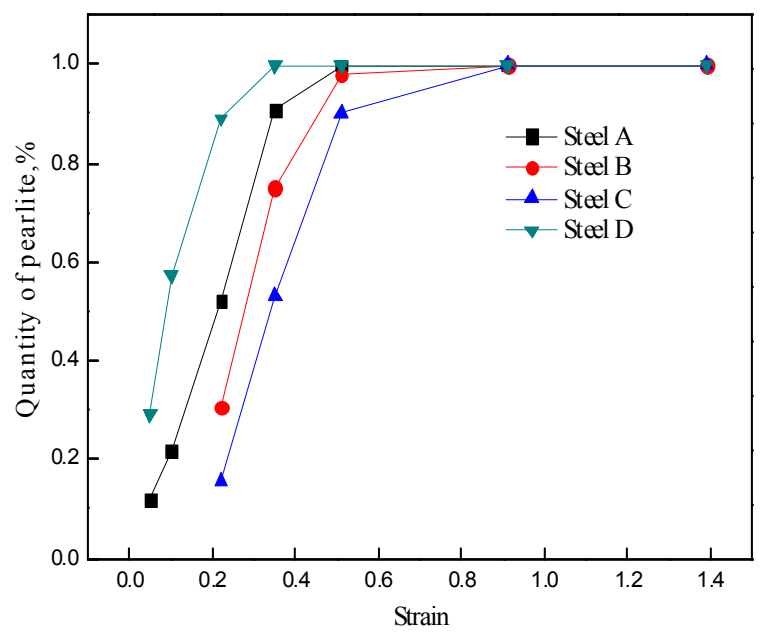

Figure 4. Fractions of deformation-induced pearlite for various strains.
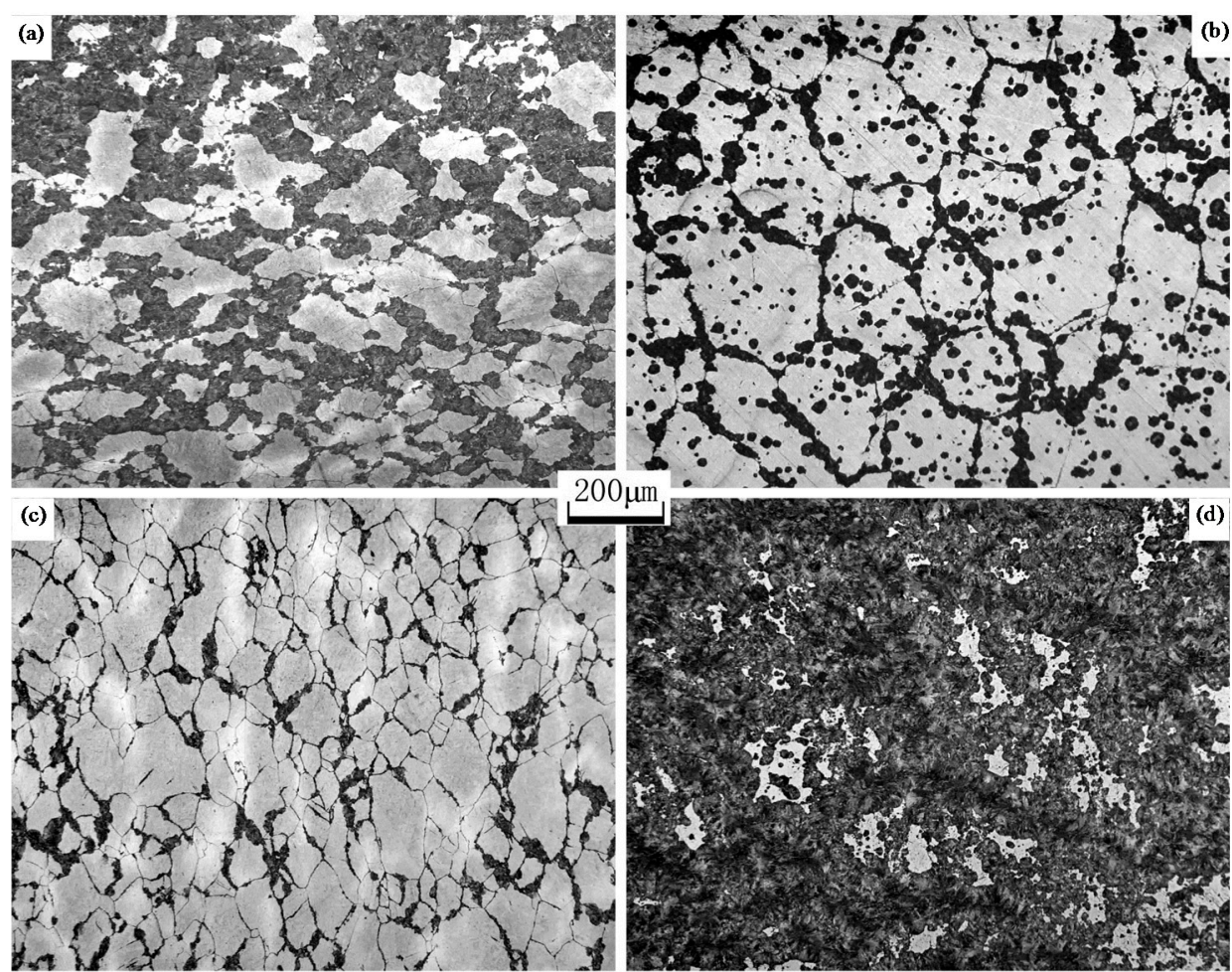

Figure 5. Deformation-induced pearlite at a strain of 0.22 in (a) Steel A, (b) Steel B, (c) Steel C, and (d) Steel D.

According to the precipitation of vanadium discussed above, the dissolved vanadium did not precipitate until the strain attained 0.91 in Steels B and C, thus indicating that the pearlite 
transformation was postponed and restrained by the dissolved vanadium in the steels when the amount of strain was below 0.91 . However, in Steel D with the addition of $\mathrm{N}$, the dissolved vanadium precipitated when the amount of strain was only 0.05 , thus indicating that the retardation was eliminated. Furthermore, the formation of ferrite was improved by the precipitation of vanadium nitrides or carbonitrides as vanadium nitrides or carbonitrides could act as the nucleus of ferrite [20]. When carbonitrides were precipitated, carbon-poor areas would appear because of carbon consumption by carbonitrides and further lead to formation of ferrite [32]. The morphology of deformation-induced pearlite at a strain of 0.05 in Steels $A$ and D is shown in Figure 6. It shows that proeutectoid ferrite occupy the boundary of austenite grain in Steel D. However, only a small amount of proeutectoid ferrite distribute at the boundary of austenite grain in Steel A, as shown in Figure 6a,b. The formation of ferrite resulted in the appearance of carbon-rich areas, thus leading to the nucleation of pearlite. Pearlite nucleated and grew up along the boundary of proeutectoid ferrite, thus leading to a higher fraction of deformation-induced pearlite in Steel D as compared to that in Steel A. In addition to the promotion of pearlite along the boundary of austenite grain (AG pearlite), the precipitation of vanadium nitrides or carbonitrides also facilitated the formation of intragranular pearlite (IG pearlite). As shown in Figure $6 c, d$, pearlite is only distributed along the austenite grain boundary in Steel A but both along and inside the grain in Steel $\mathrm{D}$ because the precipitation of nitrides or carbonitrides facilitated the formation of pearlitic ferrite inside the grain and the nucleation of intragranular pearlite (IG pearlite) was improved. As discussed in Section 3.2, if vanadium nitrides or carbonitrides were not precipitated in austenite, the rate of DIPT in Steel D would not be so faster than other V-bearing Steels $B$ and $C$.

As for Steel C, dissolved vanadium promoted a film of ferrite along the prior austenite grain boundary because vanadium should lower the composition of the eutectoid point [33] and thus the nucleation of pearlite was improved, as shown in Figure 7, ferrite and pearlite are observed along the whole boundary of austenite. However, the growth of pearlite was restrained by dragging of the dissolved vanadium [32], as a result, less pearlite was formed.
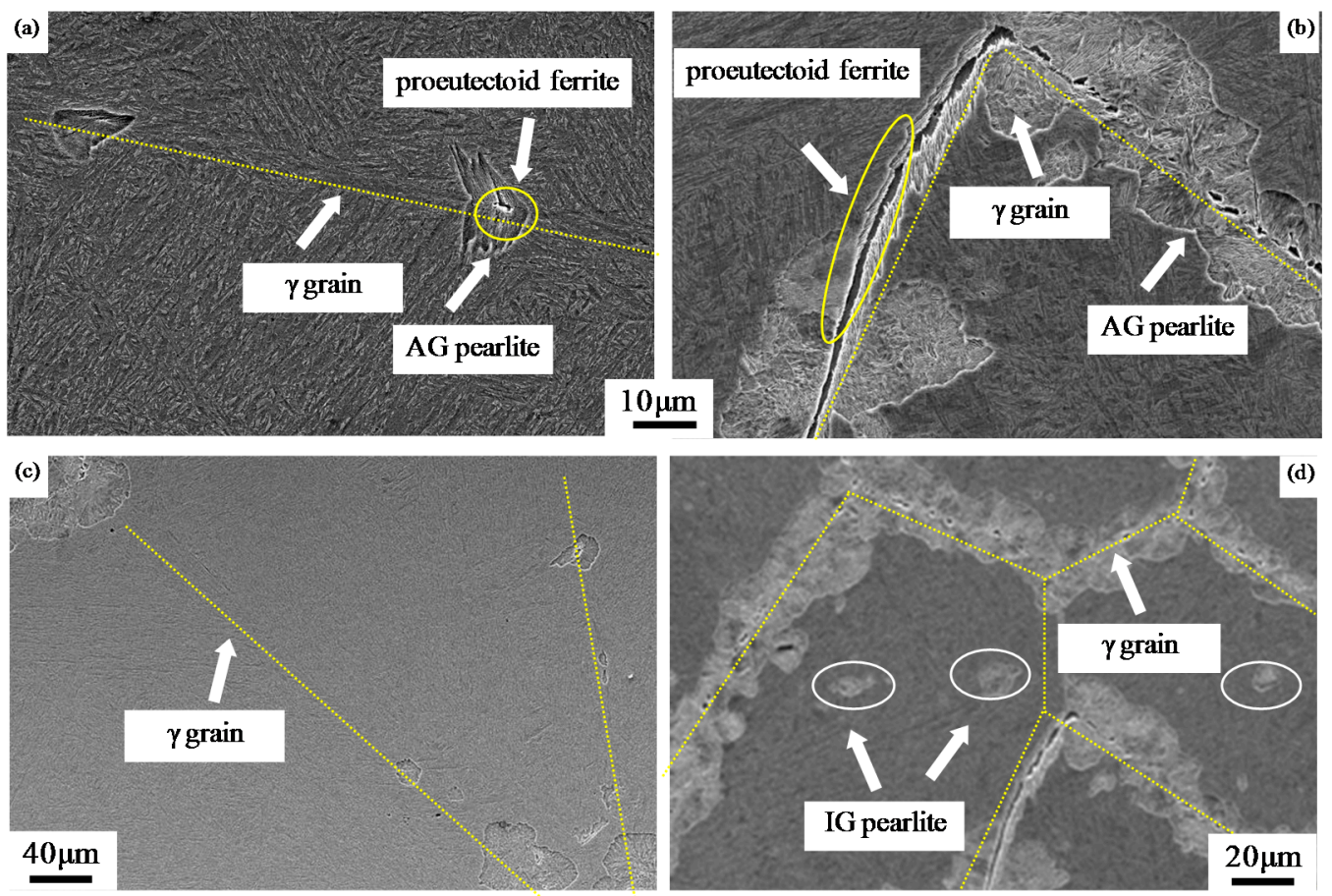

Figure 6. Morphology of deformation-induced pearlite at a strain of 0.05 in $(\mathbf{a}, \mathbf{c})$ Steel A and $(\mathbf{b}, \mathbf{d})$ Steel D. 
According to the kinetic of DIPT, the relationship between the fraction of deformation-induced pearlite $(f)$ and the time of deformation $(t)$ is expressed as follows [34]:

$$
f(x)=1-\exp \left(B t^{n}\right)
$$

where $B$ and $n$ are the parameters at a certain deformation temperature and steady stress. The fractions of deformation-induced pearlite in Figure 4 were used for the fitted kinetics of DIPT in Steels A and D. As shown in Figure 8, the end points of the austenite to pearlite transformation of Steels D and A are $36 \mathrm{~s}$ and $75 \mathrm{~s}$, respectively, which indicates that the critical strain to ensure complete transformation of pearlite at a strain rate of $0.01 \mathrm{~s}^{-1}$ are 0.36 and 0.75 , respectively. The rate of DIPT in Steel D was twice as fast as that in Steel A.

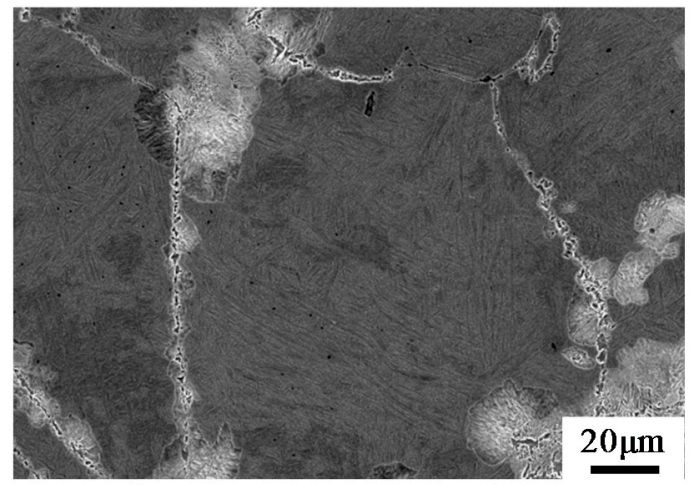

Figure 7. Morphology of deformation-induced pearlite at a strain of 0.22 in Steel C.

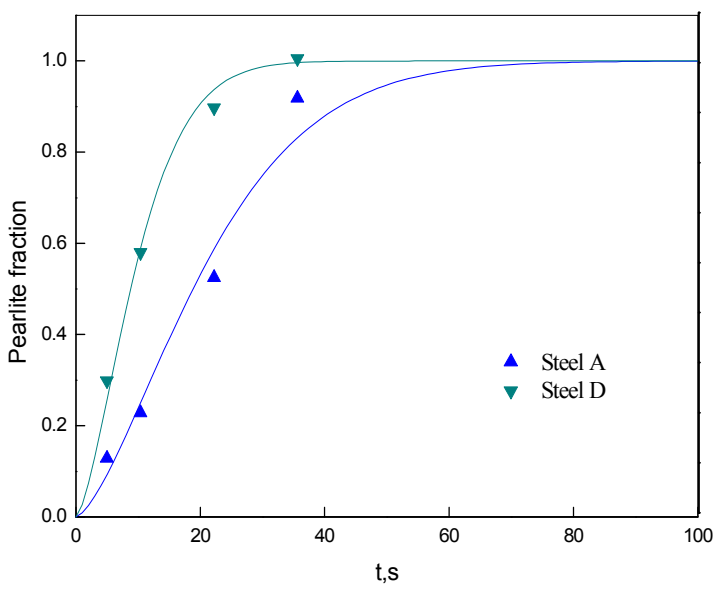

Figure 8. The fitted kinetics of DIPT in Steels A and D.

\subsection{Misorientation Angle and Grain Size of Ferrite}

As shown in Figure 9, the following processes would take place in the deformation-induced pearlite with the increase in strain: the dissolution and spheroidization of cementite, the recovery and recrystallization of ferrite, and the precipitation of finer cementite particle inside ferrite grains [35]. At a strain of 0.22 , pearlite presented the morphology of lamella; when the strain was increased to 0.51, lamellar cementites were extruded to bent or broken-up under stress; as the strain achieved a value of 0.91 , the broken-up cementites were spheroidized; and when the strain was increased to 1.39, the recrystallization of ferrites (both proeutectoid ferrite and pearlitic ferrite) and the precipitation of finer cementite particles inside ferrite grains were observed. After recrystallization, the low-angle ferrite grains $\left(0-15^{\circ}\right)$ flattened by deformation transformed to high-angle $\left(>15^{\circ}\right)$ and equiaxial ferrite grains. The possible procedures are the accumulation of dislocations at the subgrain boundaries [36], the increase of misorientation angle by the merging of lower angle boundaries during subgrain 
coalescence [37,38], and the growth of subgrain with the migration of low-angle boundaries through dislocation motion $[39,40]$. However, a fine dispersion of cementite particles was present in the microstructure as a result of the lamellae spheroidization. These particles lead to a high dragging force for the migration of high-angle grain boundaries because of the Zener pinning of the boundaries and, thus, the recrystallization and coarsening of ferrite were restrained [34].

Figure 10 shows the misorientation angles of ferrites at a strain of 1.39 in Steels A, B, C, and D, whereas Figure 11 shows the distribution of the misorientation angles. Steel D and Steel C show the maximum and minimum fraction of recrystallized ferrite, respectively, with a high angle $\left(>15^{\circ}\right)$. This result is consistent with the transformation rate of deformation-induced pearlite. The earlier the transformation will finish, the more will be the recrystallization of the formed microstructure, and thus the more uniform microstructure will be obtained, as shown in Figure 12. Steel D shows the most uniform ferrite grains, the average diameter of high-angle grains is $0.92 \mu \mathrm{m}$, on the other hand, diameter of ferrite grains in Steel A and especially in Steel C varies greatly and the average diameters of high-angle grains are $0.86 \mu \mathrm{m}$ and $0.65 \mu \mathrm{m}$, respectively. Although vanadium lowered the diffusion coefficient of carbon atoms and precipitations retarded movement of dislocation [40], the rapid transformation offered more time for the low-angle ferrite to recrystallize and coarsen. However, the fact that Steel B exhibits a higher fraction of recrystallized ferrite as compared to Steel A is not consistent with the rule as transformation in Steel B finished later, that reason may be further studied.
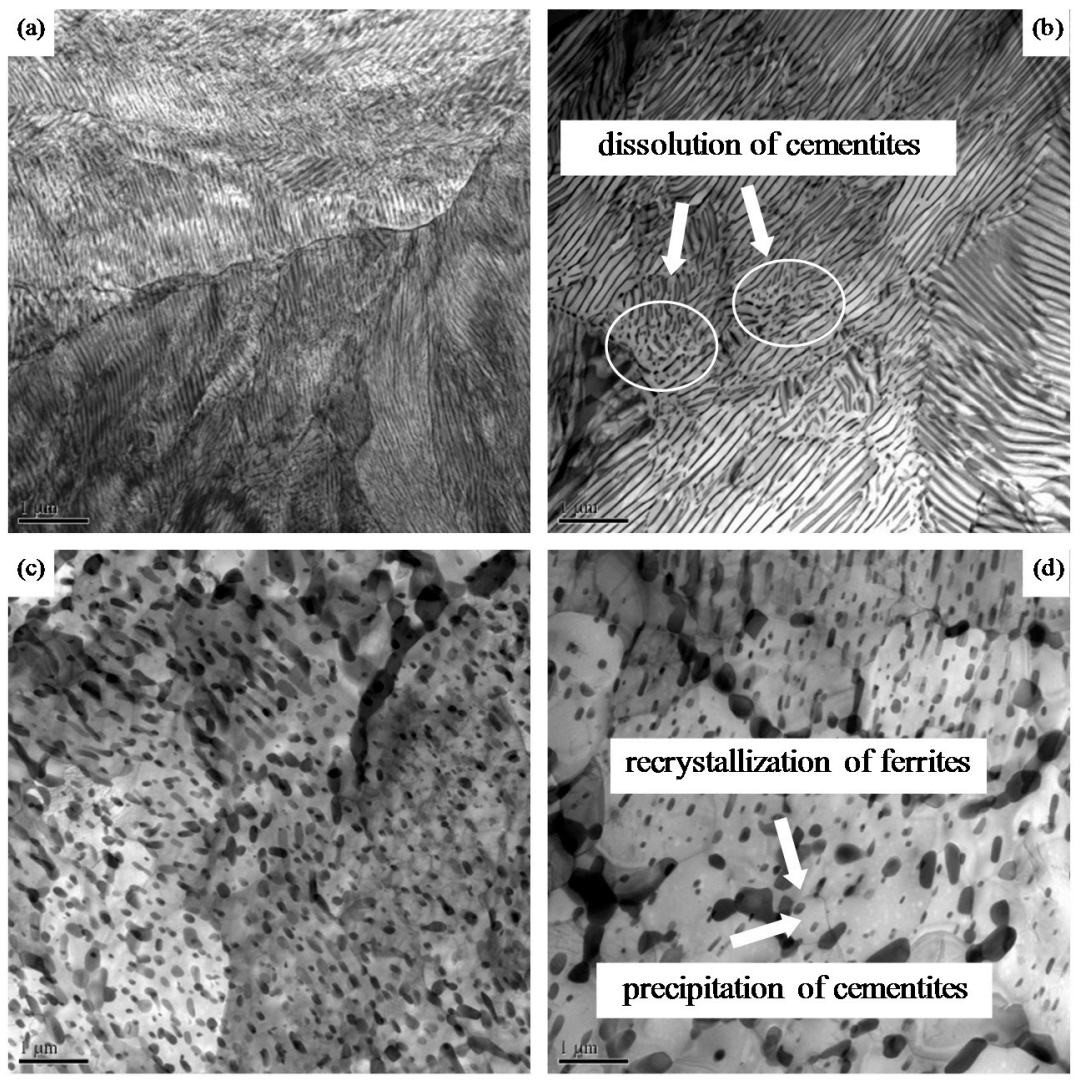

Figure 9. Microstructures observed in thin foils of Steel A obtained by quenching following the deformation for various strains: (a) 0.22 , (b) 0.51 , (c) 0.91 , and (d) 1.39 . 


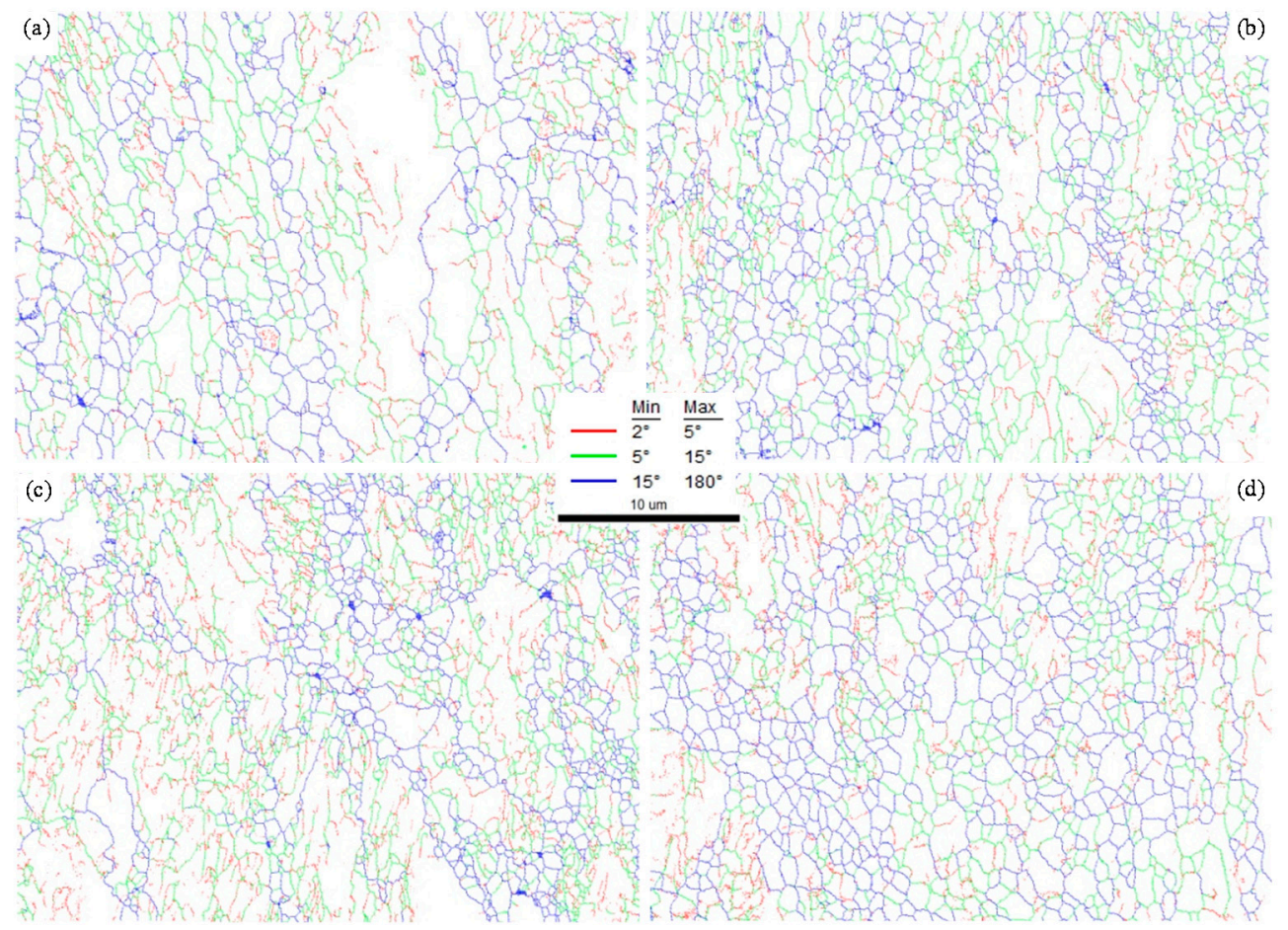

Figure 10. The misorientation angles of ferrite at a strain of 1.39 in (a) Steel A, (b) Steel B, (c) Steel C, and (d) Steel D.

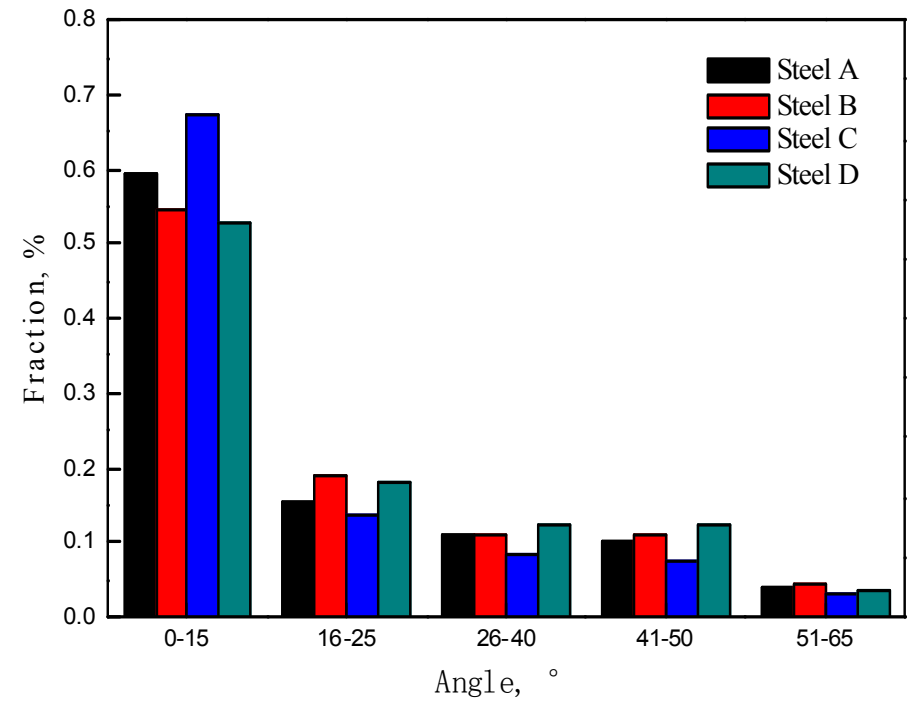

Figure 11. Distribution of misorientation angles of ferrite at a strain of 1.39 in Steels A, B, C, and D. 

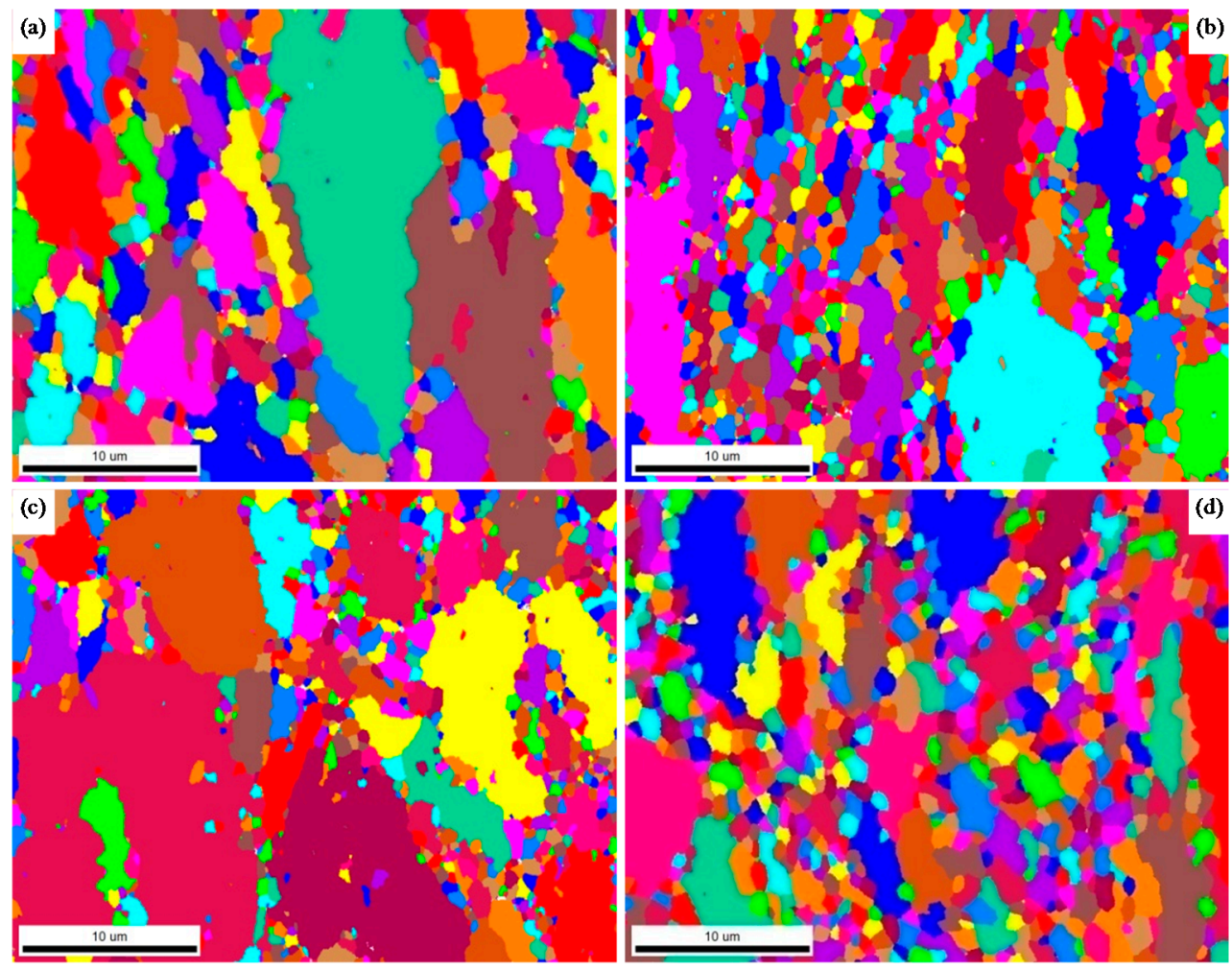

Figure 12. Ferrite grain size at a strain of 1.39 in (a) Steel A, (b) Steel B, (c) Steel C, and (d) Steel D.

\subsection{Spheroidization of Cementites}

Spheroidization of lamellar cementites can be accelerated under deformation. In the process of deformation, lamellar cementites were first cut perpendicular to the cementite by dislocations [41]; as a result, numerous lamellae with small radii were formed, as shown in Figure 13a. The equilibrium carbon concentration in ferrite in the vicinity of the lamella with a small curvature radius is higher as compared to that of a large curvature radius [25,42]. The local difference between the equilibrium carbon concentrations improved the dissolution of lamellae. Furthermore, in the case of spheroidization, the rate controlling step is the diffusion of $C[43,44]$, an excess of accumulated dislocations via movement and vacancies near lamellae kinks formed during the deformation will promote carbon diffusion [42], thus spheroidization of lamellar cementites was accelerated [40]. As shown in Figure 13b, the cementites dissolve near accumulated dislocation nets. However, dispersed vanadium carbides, nitrides or carbonitrides provided a large number of obstacles for the movement and accumulation of dislocation because vanadium carbides, nitrides, or carbonitrides exerted pinning force on dislocations. As shown in Figure 14, dislocations are pinned by fine dispersed carbonitrides and randomly distributed. The acceleration of carbon diffusion owing to the accumulated dislocations under the action of deformation was weakened by pinning of vanadium carbides, nitrides, or carbonitrides. Moreover, the diffusion rate of carbon was reduced because of the utilization of carbon by precipitates and the dragging of dissolved vanadium [45]. Figure 15 shows the morphology of cementites at a strain of 0.91 in Steels A, B, C, and D. Cementites in Steel A showed almost completely spheroidized. However, there were still a large proportion of unspheroidized cementites in Steels B, C, and D. As a result, a greater amount of strain was required to ensure the complete spheroidization of lamellar cementites. When the strain attained a value of 1.39 , the lamellar cementites were completely spheroidized in Steels B, C, and D, as shown in Figure 16. 

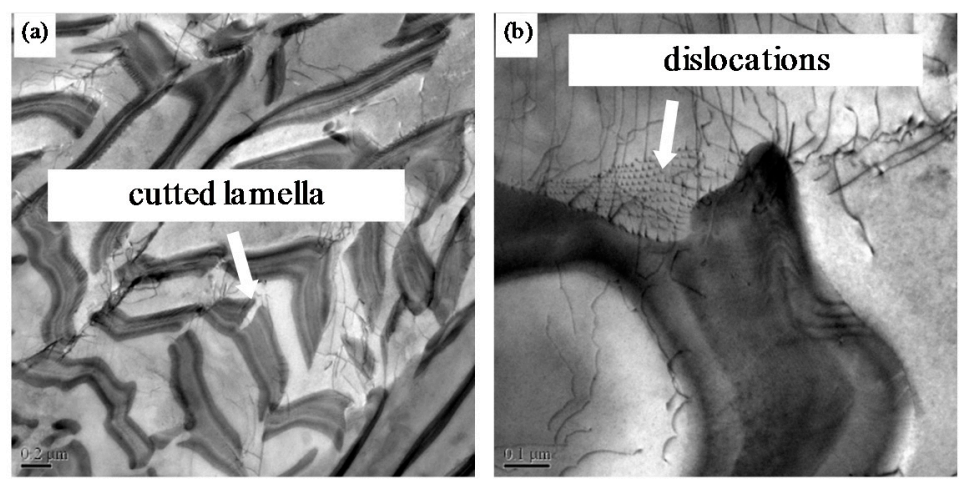

Figure 13. Dislocations at a strain of 0.22 in Steel A: (a) lamellae are cut by dislocations, and (b) lamellae dissolve near accumulated dislocation nets.

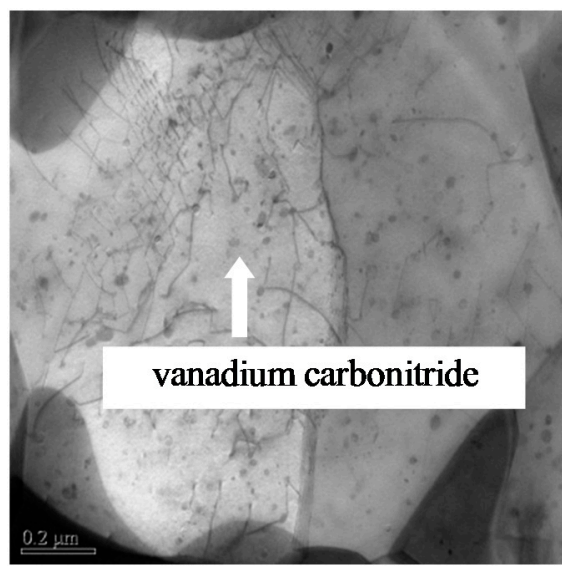

Figure 14. Dislocations are pinned by vanadium nitrides or carbonitrides in Steel D.
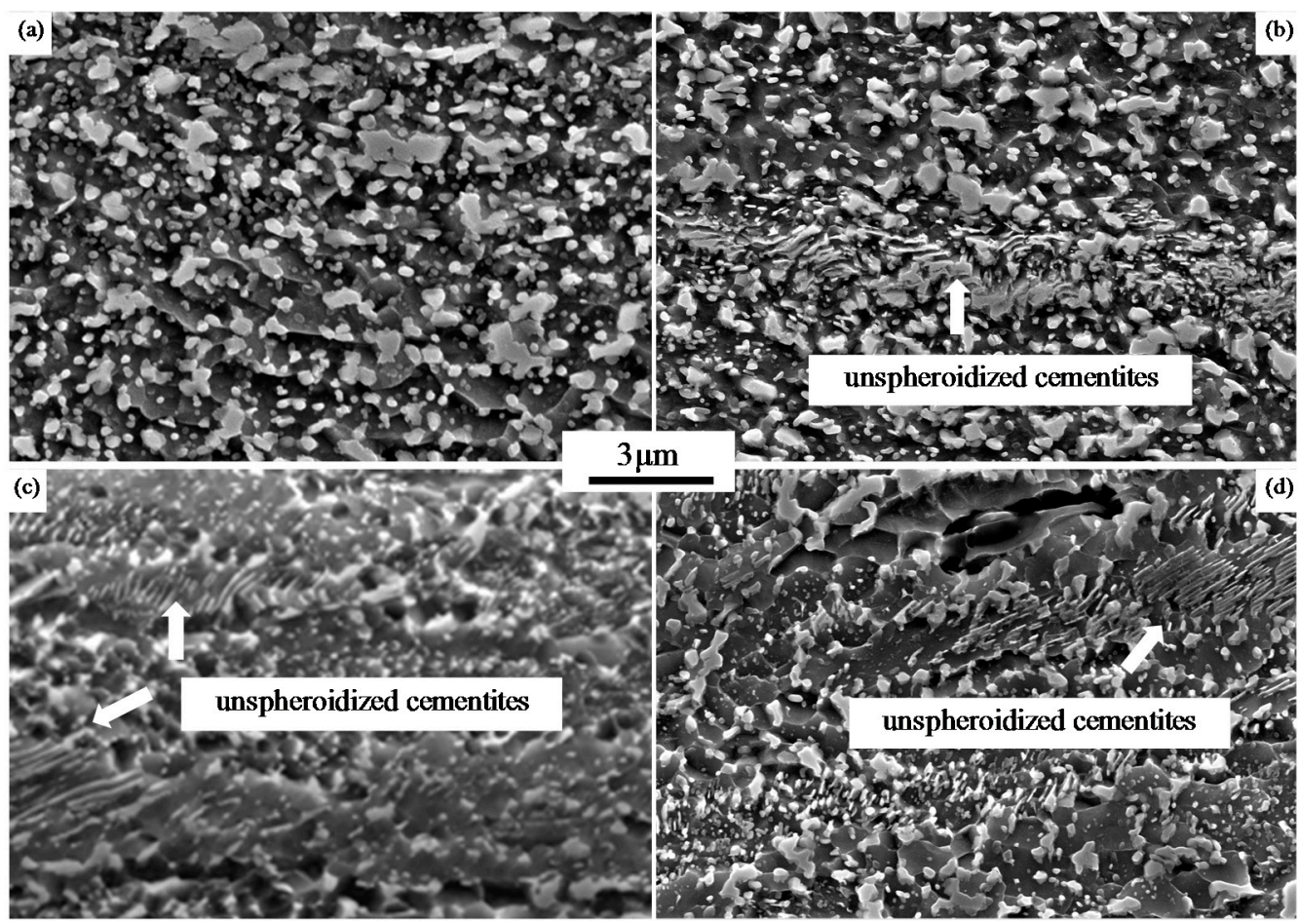

Figure 15. Morphology of cementites at a strain of 0.91 in (a) Steel A, (b) Steel B, (c) Steel C, and (d) Steel D. 

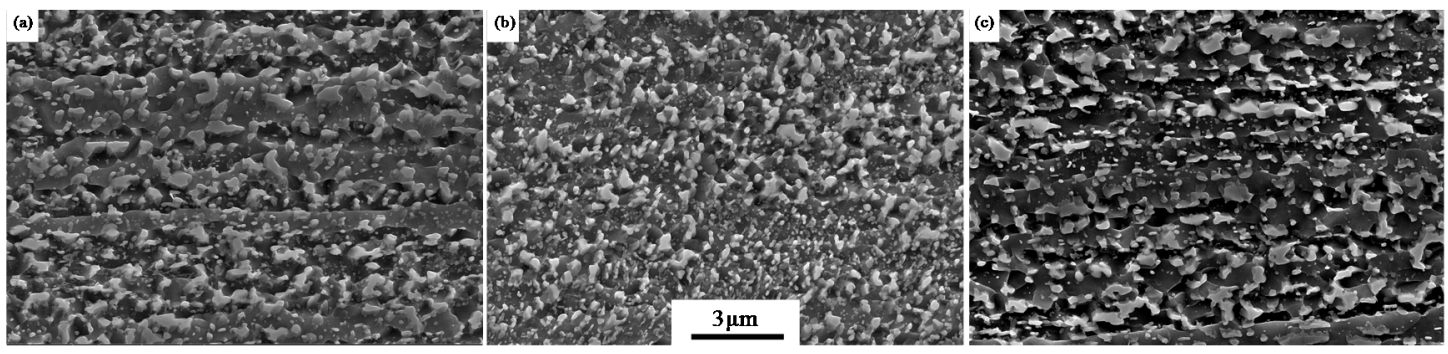

Figure 16. Morphology of cementites at a strain of 1.39 in (a) Steel B, (b) Steel C, and (c) Steel D.

\section{Conclusions}

(1) Vanadium in Steels B, C, and D was completely dissolved in austenite at an austenization temperature of $1150{ }^{\circ} \mathrm{C}$. The pearlite transformation at a cooling rate of $20^{\circ} \mathrm{C} / \mathrm{s}$ was postponed and restrained at the dissolved vanadium content of 0.1 mass \% in Steels B and D, especially at $0.27 \mathrm{wt} \%$ in Steel C. During the deformation, vanadium carbides in Steels B and C were precipitated in ferrite when the strain value was 0.91 . However, vanadium nitrides or carbonitrides in Steel D were precipitated in austenite under a small deformation with a strain of 0.05 as vanadium has a higher affinity for nitrogen as compared to carbon, and the precipitation of vanadium can significantly be improved by the addition of $\mathrm{N}$.

(2) The fraction of deformation-induced pearlite increased with the increase of strain in all the steels, and the fractions in vanadium-microalloyed Steels B and C were lower as compared to that in vanadium-free Steel $A$ at the same strain level before the contained vanadium began to precipitate because the dissolved vanadium postponed and restrained DIPT.

(3) The fraction of deformation-induced pearlite in Steel D was higher as compared to that in Steel A because the precipitation of vanadium nitrides or carbonitrides facilitated the formation of proeutectoid ferrite along the boundary of austenite grain and pearlitic ferrite inside the grain by acting as a nucleus. Thus, the nucleation of pearlite along the boundary of austenite grain (AG pearlite) and intragranular pearlite (IG pearlite) was improved because of carbon gathering due to the formation of ferrite.

(4) The spheroidization speed of cementites in Steels B, C, and D with vanadium microalloying was slower as compared to that in Steel A because vanadium carbides, nitrides, or carbonitrides and dissolved vanadium reduced the diffusion rate of carbon.

(5) Steel D microalloyed with vanadium and with the addition of $\mathrm{N}$ showed the optimal microstructure with the maximum fraction of the recrystallized ferrite and the most uniform ferrite grain size and completely spheroidized cementites when the strain attained a value of 1.39, the reason is because the rate of pearlite transformation in Steel D was the fastest and the "pancake" ferrite took more time to recrystallize.

Author Contributions: Writing—original draft preparation, Z.C.; writing—review and editing, S.B.; supervision, X.M.; project administration, G.Z.; funding acquisition, Y.X.

Funding: This research was funded by National Key R\&D Program of China No. 2017YFB0304800.

Conflicts of Interest: The authors declare no conflict of interest.

\section{References}

1. Lutsenko, V.A.; Matochkin, V.A.; Khudolei, Y.L.; Chernichenk, V.G.; Lutsenko, O.V. Influence of thermomechanical treatment and alloying on the properties of high carbon wire rod. Steel Transl. 2010, 40, 853-856. [CrossRef]

2. Zhuchkov, S.M.; Matochkin, V.A.; Gorbanev, A.A. Production of high-quality wire rod. Steel Transl. 2007, 37, 448-452. [CrossRef] 
3. Verlinden, B.; Driver, J.; Samajdar, I.; Doherty, R.D. Thermo-mechanical processing of steel. In ThermoMechanical Processing of Metallic Materials; Elsevier: London, UK, 2007.

4. Wu, S.; Li, X.C.; Zhang, J.; Shang, C.J. Effect of $\mathrm{Nb}$ on transformation and microstructure refinement in medium carbon steel. Acta Metall. Sin. 2014, 50, 400-408.

5. Wu, T.; Gao, Y.W.; Wang, M.Z. Influence of initial microstructure on warm deformation processability and microstructure of an ultrahigh carbon steel. J. Iron Steel Res. Int. 2014, 21, 52-59. [CrossRef]

6. Holtzman, A.H.; Danko, J.C.; Stout, R.D. Spheroidization of cold-worked pearlite. Trans. Met. Soc. AIME 1958, 212, 475-478.

7. Lu, Z.Q.; Zhang, H.F.; Meng, Q. Effect of cyclic annealing on microstructure and mechanical properties of medium carbon steel. J. Iron Steel Res. Int. 2016, 23, 145-150. [CrossRef]

8. Ji, C.; Wang, L.; Zhu, M.Y. Effect of subcritical annealing temperature on microstructure and mechanical properties of SCM435 steel. J. Iron Steel Res. Int. 2015, 22, 1031-1036. [CrossRef]

9. Tao, W.; Wang, M.Z.; Gao, Y.W.; Li, X.P.; Zhao, Y.C.; Zou, Q. Effects of plastic warm deformation on cementite spheroidization of a eutectoid steel. J. Iron Steel Res. Int. 2012, 19, 60-66.

10. Li, L.; Yang, W.; Sun, Z. Effects of Particle Size on Mechanical Properties of a TiC Containing Tool Steel by Hot Isostatic Press. Met. Mat. Trans. 2008, 39, 624-629. [CrossRef]

11. Hickson, M.R.; Gibbs, R.K.; Hodgson, P.D. The Effect of Chemistry on the Formation of Ultrafine Ferrite in Steel. ISIJ Int. 1999, 39, 1176-1182. [CrossRef]

12. Zhang, S.L.; Sun, X.J.; Dong, H. Mechanism of Austenite Evolution during Deformation of Ultra-High Carbon Steel. J. Iron Steel Res Int. 2008, 15, 42-46. [CrossRef]

13. Huang, Q.S.; Li, L.F.; Yang, W. Dynamic Transformation of Undercooling Austenite and Microstructure Refinement in a Eutectoid Steel. Acta Metall. Sin. 2007, 43, 724-730.

14. Chen, W.; Li, L.F.; Yang, W.Y. Microstructure Evolution of Hypereutectoid Steels During Warm Deformation I. Formation of Equiaxial Ferrite and Effects of Al. Acta Metall. Sin. 2009, 45, 151-155.

15. Rastegari, H.; Kermanpur, A.; Najafizadeh, A.; Porter, D.; Somani, M. Warm Deformation Processing Maps for the Pain Eutectoid Steels. J. Alloy Compd. 2015, 626, 136-144. [CrossRef]

16. Xiong, Y.X.; Fu, W.T.; Li, Y. Warm Deformation Behavior of High Carbon Steel. J. Iron Steel Res. Int. 2007, 19, 58-63.

17. Zhang, S.L.; Sun, X.J.; Dong, H. Effect of Deformation on the Evolution of Spheroidization for the Ultra High Carbon Steel. Mater. Sci. Eng. A 2006, 432, 324-332. [CrossRef]

18. Li, J.; Choi, P.; Borchers, C.; Westerkamp, S.; Goto, S.; Raabe, D.; Kirchheim, R. Atomic-scale Mechanisms of Deformation-induced Cementite Decomposition in Pearlite. Acta Mater. 2011, 59, 3965-3977. [CrossRef]

19. Han, K.; Mottishaw, T.D.; Smith, G.D.; Edmonds, D.V.; Stacey, A.G. Effects of Vanadium Additions on Microstructure and Hardness of Hypereutectoid Pearlitic Steels. Mater. Sci. Eng. A 1995, 190, 207-213. [CrossRef]

20. Jaiswal, S.; McIvor, I.D. Metallurgy of Vanadium-Microalloyed High-carbon Steel rod. Mater. Sci. Technol. 1985, 1, 276-283. [CrossRef]

21. Izotov, B.I. Precipitation of Disperse Vanadium Carbides at the Interphase Boundary upon the Pearlitic Transformation of a Steel. PMM 2011, 111, 592-597. [CrossRef]

22. Li, L.; Virta, J. Ultrahigh Strength Steel Wires Processed by Severe Plastic Deformation for Ultrafine Grained Microstructure. Mater. Sci. Tech. 2011, 27, 845-862. [CrossRef]

23. Matlock, D.K.; Speer, J.G. Microalloying Concepts and Application in Long Products. Mater. Sci. Technol. 2009, 25, 1118-1125. [CrossRef]

24. Li, Y.; Yang, Z.M. The Effects of V on Phase Transformation of High Carbon Steel during Continuous Cooling. Acta Metall. Sin. 2010, 46, 1502-1510.

25. Hu, X.J.; Zhao, Y.F.; Wang, L. Effect of Vanadium on the Microstructure and Properties of High Carbon Steel Wires. Iron \& Steel 2014, 49, 71-75.

26. Wang, K.; Yu, H.Y.; He, J.C. Influence of Cooling Rate on Microstructure Evolution Due to Deformation Induced Ferrite Transformation in Vanadium Microalloyed Steel. J. Northeastern Univ. 2009, 30, 1740-1742.

27. Wang, K.; Wang, L.J.; Cui, W.F. Effect of Vanadium and Vanadium-N Microalloying on Deformation -Induced Ferrite Transformation in Low Carbon Steels. J. Mater. Sci. Technol. 2006, 22, 159-163. [CrossRef]

28. Sharma, R.C.; Lakshmanan, K.; Kirkaldy, J.S. Solubility of Niobium Carbide and Niobium Carbonitride in Alloyed Austenite and Ferrite. Metall. Mater. Trans. A 1984, 15, 545-553. [CrossRef] 
29. Karmakar, A.; Mukherjee, S.; Kund, S.; Srivastava, D.; Mitra, R.; Chakrabarti, D. Effect of Composition and Isothermal Holding Temperature on the Precipitation Hardening in Vanadium-microalloyed steels. Mater. Charact. 2017, 132, 31-40. [CrossRef]

30. Rune, L.; Bevis, H.; Tadeusz, S.; Stanislaw, Z. The Role of Vanadium in Microalloyed Steels. Scand. J. Metall. 1999, 28, 186-241.

31. Liu, Q.C.; Yong, Q.L.; Zheng, Z.W. Effect of Nitrogen on the Vanadium Precipitation Behavior of Higher Yield Strength Weathering Steels. In HSLA Steels 2015, Microalloying 2015 E Offshore Engineering Steels 2015; Springer: Cham, Switzerland, 2016.

32. Han, K.; Mottishaw, T.D.; Smith, G.D.W.; Edmonds, D.V.; Stacey, A.G. Effects of Vanadium Addition on Nucleation and Growth of Pearlite in High Carbon Steel. Mater. Sci. Tech. 1994, 10, 955-963. [CrossRef]

33. Khalid, F.A.; Edmonds, D.V. Effect of Vanadium on the Grain Boundary Carbide Nucleation of Pearlite in High-carbon Steels. Scr. Metal. Mater. 1994, 30, 1251-1255. [CrossRef]

34. Hsu, T.Y. Additivity Hypothesis and Effects of Stress on Phase Transformations in Steel. Curr. Opin. Sol. Stat. Mater. Sci. 2005, 9, 256-268.

35. Chen, W.; Li, L.F.; Yang, W.Y. Microstructure Evolution of Hypereutectoid Steels during Warm Deformation II. Cementite Spheroidization and Effects of Al. Acta Metall. Sin. 2009, 45, 156-160.

36. Hales, S.; McNelley, T.; McQueen, H. Recrystallization and Superplasticity at $300{ }^{\circ} \mathrm{C}$ in an Aluminummagnesium Alloy. Metall. Mater. Trans. A 1991, 22, 1037-1043. [CrossRef]

37. Haessner, F. Recrystallization of Metallic Materials; Dr. Riederer Verlag: Stuttgart, Germany, 1978; p. 159.

38. Hornbogen, E. Combined reactions. Metall. Mater. Trans. A 1979, 10, 947. [CrossRef]

39. Baudelet, B.; Surey, M. Superplasticity; Centre National de la Recherche Scientifique: Paris, France, 1985; Volume 7, pp. 1-14.

40. Storojeva, L.; Ponge, D.; Kaspar, R.; Raabe, D. Development of Microstructure and Texture of Medium Carbon Steel during Heavy Warm Deformation. Acta. Materialia. 2004, 52, 2209-2220. [CrossRef]

41. Zhao, Y.G.; Tan, Y.B.; Ji, X.M.; Xiang, Z.J.; He, Y.; Xiang, S. In Situ Study of Cementite Deformation and its Fracture Mechanism in Pearlitic Steels. Mater. Sci. Eng. A 2018, 731, 93-101. [CrossRef]

42. Chattopadhyay, S.; Sellars, S. Kinetics of Pearlite Spheroidisation during Static Annealing and during Hot Dformation. Acta Met. 1982, 30, 157-170. [CrossRef]

43. Tian, Y.L.; Kraft, R.W. Kinetics of Pearlite Spheroidization. Metall. Trans. A. 1987, 18, 1359-1369. [CrossRef]

44. Cree, A.M.; Faulkner, R.G.; Lyne, A.T. Cementite Particle Coarsening During Spheroidisation of Bearing Steel SAE 52100. Mater. Sci. Technol. 1995, 11, 566-571. [CrossRef]

45. Jorge-badiola, D.; Iza-mendia, A.; López, B.; Rodriguez-ibabe, J.M. Role of Vanadium Microalloying in Austenite Conditioning and Pearlite Microstructure in Thermomechanically Processed Eutectoid Steels. ISIJ Int. 2009, 49, 1615-1623. [CrossRef]

(C) 2019 by the authors. Licensee MDPI, Basel, Switzerland. This article is an open access article distributed under the terms and conditions of the Creative Commons Attribution (CC BY) license (http://creativecommons.org/licenses/by/4.0/). 